\title{
Importance of Antenatal Care Services to Pregnant Women at the Buea Regional Hospital Cameroon
}

\author{
Samuel Nambile Cumber ${ }^{1,2, *}$, Dioni Christabel Diale ${ }^{2}$, Elive Mbua Stanly ${ }^{2}$, Nina Monju ${ }^{2}$ \\ ${ }^{1}$ Discipline of Public Health Medicine, Department of Nursing \& Public Health, College of Health Sciences, University of Kwazulu-Natal \\ Durban, South Africa \\ ${ }^{2}$ Under Privilege Children and Women Assistance (UPCAWA-SWEDEN), Buea, Cameroon
}

\author{
Email address: \\ samuelcumber@yahoo.com (S. N. Cumber) \\ *Corresponding author
}

\section{To cite this article:}

Samuel Nambile Cumber, Dioni Christabel Diale, Elive Mbua Stanly, Nina Monju. Importance of Antenatal Care Services to Pregnant Women at the Buea Regional Hospital Cameroon. Journal of Family Medicine and Health Care. Vol. 2, No. 4, 2016, pp. 23-29. doi: $10.11648 /$ j.jfmhc.20160204.11

Received: September 21, 2016; Accepted: October 5, 2016; Published: November 2, 2016

\begin{abstract}
It is known from studies that the morbidity and mortality of pregnant women who attend antenatal care is reduced compared to women who do not attend antenatal care. That is why this study aimed at assessing the antenatal care services of pregnant women with the objective to determine the knowledge, know the importance of ANC and finally now the factors that hinder women from attending ANC. In this study, a descriptive cross-sectional designed was used, and a sample random sampling method was used to select a total of 50 participants. A well structured questionnaire was used to collect data. Data was analyzed using micro-soft excel version 2007 and the results were represented on tables. Findings showed that majority $92 \%$ of these pregnant women have knowledge on the importance of ANC, In addition, Majority 38\% of these pregnant complained of poverty as their major hindrance, It was concluded that women had knowledge on antenatal care and we concluded that the hospital administration should reduce the fee of antenatal care so that the pregnant women will be encouraged to attend.
\end{abstract}

Keywords: Antenatal, Care Services, Pregnancy, Women, Cameroon

\section{Introduction}

Antenatal care (ANC) services are defined as an umbrella term used to describe the medical procedures and care carried out during pregnancy. [1] Antenatal care, a pregnancy related services provided to pregnant women by health professionals, is among the Millennium Development Goal (MDGs) 4 and 5 , the major interventions which is aimed at preventing Neonatal death and maintaining the health of the women during pregnancy.[2, 3] ANC has many component such as laboratory investigation, referral, health education etc. [3]

Antenatal care (ANC) is very important to pregnant women as it helps prevent mother and child mortality, prevent complications help foster a good relationship between the husband and wife, mother and child and father and child. $84.7 \%$ of pregnant women have at least one ANC contact with skilled personnel. [4] However, to achieve the full life saving potential that ANC promises for women and babies four visits providing essential evidence based intervention. In the $1914 \mathrm{~s}$ study by William, ANC reduced fetal mortality by $40 \%$. [3]

The wide spread coverage of ANC is largely responsible for $80 \%$ globally of pregnant women access to ANC at least once with a skilled health personnel. Only half (51\%) of pregnant women worldwide received the recommended amount i.e. four visit of care during pregnancy. $[3,5]$

In some cases, some pregnant women still present with complications e.g. hemorrhage, hypertensive disorder, pregnancy related infection, pre-eclampsia and eclampsia. ANC can help women prepared for delivery and understand warning signs during pregnancy and childbirth. It can be a source for micronutrient supplementation, treatment for pregnancy induced hypertension to prevent pre-eclampsia and eclampsia. ANC act as a route to provide immunization against tetanus, HIV testing and medication to prevent 
Mother To- Child Transmission (PMTCT) in case of HIV positive pregnant women. In cases malaria is endemic, health personnel can also provide pregnant women with medication and insecticide treated mosquito net to help prevent this debilitating sometimes deadly disease. [3,5]

Lastly although this ANC is important for these pregnant women, they are some factors that hinder these women from using ANC such as poverty because some of them cannot meet up to the standard of paying their laboratory bills and other things which the hospital may ask them. Also lack of health facilities in some remote areas makes these women to feel reluctant to attend ANC.

Historically, the traditional ANC service model was developed in the early 1900s in USA by Campbell. It began with home nurse visit and the first prenatal clinic was established in 1911. During the 1920s, Dame Janet Campbell played great role and her ideas became the clinical obstetric screening service of the 1930s. By the 1950s, a schedule of monthly visit to 28 weeks, fortnightly visits to 36 weeks visits until birth had become standard. [5, 6]

With the development of the Millennium Development Goals (MDGs) in 1990 by UNICEF, WHO, UN, there are eight areas of concern that the entire world is involved to achieved by 2015, these include; Eradicate extreme poverty, achieve universal primary education, promote gender equality and empower women, combat HIV/AIDs, malaria and other disease, ensure environmental sustainability, global partnership for development. [5, 6]

With the development of the MDGs, improving maternal health is the fifth item on the list which is subdivided into goal $\mathrm{A}$ and $\mathrm{B}$. Target $5 \mathrm{~A}$ reduce by three quarters, between 1990 and 2015, the maternal mortality ratio. Target 5B achieve by 2015 , universal access to reproductive health. [5, 6] In that light the above organization have come to work through the various keys areas;

Strengthening health systems and promoting interventions focusing on policies and strategies that work, are pro-poor and cost-effective, Monitoring and evaluating the burden of maternal and newborn ill-health and its impact on societies and their socio-economic development, Building effective partnership in order to make best use of scarce resources and minimize duplication in efforts to improve maternal and neonatal health, Advocating for investment in maternal and newborn health by high-lighting the social and economic benefits and emphasizing maternal mortality, and Coordinating research with wide-scale application, which focuses on improving maternal health in pregnancy and delivery, after childbirth. [3, 5, 6]

Although maternal death worldwide have almost halved since 1990 according to WHO latest figure, every roughly 800 women and adolescence girls die from complications of pregnancy or childbirth. In 2010, 287,000 women died during childbirth with almost all of these death (99\%) occurring in low-resources setting but a decline of $47 \%$ were recorded from all levels 1990. Most of them died because they had no access to skilled routine and emergency care. Since 1990, some countries in Asia and Northern Africa have more than halved maternal mortality. [5, 6]

The frequent visit aid is used to classifying pregnant women into low and high risk by predicting the complication ahead of time. The traditional approach was replaced by Focused Antenatal Care (FANC) a goal-oriented approach which was recommended by researcher in 2001 and adopted by WHO in 2002. [3, 5, 6] The optimal use of ANC service alone far from guaranteeing a fortunate progress of the pregnancy. [7] In 2009 and 2010 result showed that $35 \%$ of pregnant women attended the first quarter of ANC visit i.e. before the end of $12^{\text {th }}$ weeks of amenorrhea. [7]

During ANC visit, pregnant women are educated on the following important topics: nutrition, medication, lifestyle, exercise, personal and environmental hygiene, safety in the environment, etc. The extend to ANC service underutilization by pregnant women is based at the individual and family level, the crucial factors are; employment of the women, education of the women and spouse, marital status, house hold income, exposure to media, obstetrical complications, parity, age, religious belief, culture, and pre-conception of pregnancy. Among the social - demographic factors, the odds for underutilizing ANC services increased significantly for mothers with low educational attainment and from households with a low wealth index. [4, 8] Financial barriers are preventative care for which pregnant women are charged user fees according to the cost recovery scheme meanwhile the state heavily subsides the majority of ANC components. [4] Cultural belief and ideas about pregnancy also had an influence pregnancy on ANC use in that they may lead to attending ANC late or not attending at all. Parity had a statistically significant negative effect on adequate attendance, where by women of a high parity tend to attend late for the first ANC visit or have few ANC visit. Globally, over $10 \%$ of all women do not have access to or are not using an effective method of contraception. It is estimated that satisfying the unmet need for the family planning alone could cut the number of maternal deaths by almost a third. $[5,6]$ The UN Secretary-General's Global strategy for Women's and Children's Health aims to prevent 33 millions unwanted pregnancy and childbirth, including unsafe abortion. [5, 6] In this regard, this study is a contribution to deliberation aiming at the availability and applicability of ANC services to pregnant women and to reduce some complication in pregnancy by providing adequate information to pregnant women during ANC visit. [3, 5, 6]

Antenatal clinic, are a key strategy to decreasing maternal mortality in low income resource settings and it is important to pregnant women as it help prevent maternal and child mortality as well as pregnancy complications. Despite improvement in maternal and infant mortality, there are other factors which hinder these women from using ANC Services such as religion/cultural beliefs, poverty. Thus about 9,000 women lose their life during childbirth every year in Cameroon. [4] Therefore it is necessary to explore pregnant women knowledge on the importance of ANC Services so as to come to a better understanding on the factors that hinders these women from attending ANC do pregnant women. 
This study has some questions like: Do pregnant women have knowledge on the component of ANC? What are the importance of ANC? and What are the factors that hindered pregnant women from using ANC services?

The objective of the study was: To assess pregnant women knowledge on the component of ANC service, To determine the importance of ANC and to described of the factors that hindered pregnant women from attending ANC services.

This study aimed at raising awareness on the importance of the ANC services in the global community and how it could help fight some common complications during pregnancy and reduce maternal and infant morbidity in the country.

The scope of this study is to present the "Importance of ANC services to pregnant women" was carried out at the Buea Regional Hospital and involves pregnant women attending ANC.

\section{Methods and Materials}

\subsection{Research Design}

A descriptive cross-sectional survey was used.

\subsection{Study Area}

This research was carried out at Buea Regional Hospital. (BRH) is found in Fako Division of the South West Region of Cameroon at the foot of the Mt Cameroon. It is about $3 \mathrm{~km}$ away from the mile 17 motor park. The hospital is made up of several units, department, and centers each headed by a specialist doctor. the units include; Medical, Surgical, Pediatric, Psychiatric, Maternity, Tuberculosis, Diabetic center, Laboratory, Outpatient department, Theater, Pharmacy, UPEC, X ray administrative and the Mortuary. The research was carried out in the maternity

\subsection{Study Population}

The target population was pregnant women attending antenatal at the Buea regional hospital in all trimester of their pregnancy.

\subsection{Inclusion Criteria}

The study included women who understood the purpose of the study and could express themselves freely.

\subsection{Exclusion Criteria}

The study excluded those women who did not give their consent freely

\subsection{Sampling Technique}

A sample random sampling technique was used among the women who attended the attended the antenatal at the time of the study. This technique was used to prevent bias

\subsection{Sampling Size}

The sampling size was 50 pregnant women who were randomly selected.

\subsection{Instrument for Data Collection}

A structured questionnaire was the tool for data collection which was designed according to the objectives and divided into four sections namely: demography data, component of ANC, importance of ANC, and lastly factors that hinders ANC.

\subsection{Data Management and Analysis}

The collected data was kept save at the end research to prevent loss of important information. Results keyed into the computer were secured using a password to secure participant information and prevent unwanted access. This information was later copied unto a Compact Disc (CD) to serve as a reserve and for storage. Data collected was analysis using Microsoft excel 2007 version and the results were represented on tables.

\subsection{Ethical Consideration}

An authorization was obtained from school which was presented to the General Supervisor at BRH that permitted the researcher to collect information from the health unit chosen by the researcher. The data was collected and kept confidential.

\subsection{Limitation of the Study}

The major limitation was that some of the women were unwilling to respond

\section{Results}

\subsection{Demographic Data}

\subsubsection{Age}

Out of the 50 participant that were selected, majority $40(80 \%)$ were in the age group between $21-25$ while a lesser proportion $10(20 \%)$ were in the age group between 35 . Table 1

\subsubsection{Religion}

Out of the 50 participant who took part, majority $35(70 \%)$ were of the age group 25-26 while a lesser proportion1 $5(30 \%)$ of the age range $31-35$. Table 1

\subsubsection{Marital status}

As regards to the marital status, majority $36(72 \%)$ of the respondents were married while a lesser proportion $14(28 \%)$ were divorce. Table 1

\subsubsection{Level of Education}

With regard to the level of education, majority of the participants $45(90 \%)$ had advance level while a lesser proportion of the respondent $5(10 \%)$ had FSLC. Table 1

\subsubsection{Level of Profession}

Out of the 50 participant who participated majority $46(92 \%)$ were students while a lesser proportion $4(8 \%)$ were 
teaching as seen on the table 1

Table 1. Distribution of respondents by Age, Religious status, Marital status, Level of education and Profession.

\begin{tabular}{|c|c|c|c|}
\hline Demographic data & Category & Frequency & Percentage \\
\hline \multirow{6}{*}{ Age } & $16-20$ & 7 & $14 \%$ \\
\hline & $21-25$ & 17 & $34 \%$ \\
\hline & $26-30$ & 11 & $22 \%$ \\
\hline & $31-35$ & 9 & $18 \%$ \\
\hline & $35-40$ & 6 & $12 \%$ \\
\hline & Total & 50 & $100 \%$ \\
\hline \multirow{4}{*}{ Religion } & Christians & 35 & $70 \%$ \\
\hline & Muslim & 10 & $20 \%$ \\
\hline & Others & 5 & $10 \%$ \\
\hline & Total & 50 & $100 \%$ \\
\hline \multirow{4}{*}{ Marital status } & Married & 36 & $72 \%$ \\
\hline & Singles & 10 & $30 \%$ \\
\hline & Divorce & 4 & $8 \%$ \\
\hline & Total & 50 & $100 \%$ \\
\hline \multirow{5}{*}{ Level of education } & Advanced level & 20 & $40 \%$ \\
\hline & Ordinary level & 15 & $30 \%$ \\
\hline & FSLC & 4 & $8 \%$ \\
\hline & Others & 11 & $22 \%$ \\
\hline & Total & & $100 \%$ \\
\hline \multirow{7}{*}{ Profession } & Housewife & 6 & $12 \%$ \\
\hline & Students & 12 & $24 \%$ \\
\hline & Nurses & 5 & $10 \%$ \\
\hline & Teaching & 4 & $8 \%$ \\
\hline & Business & 10 & $20 \%$ \\
\hline & Others & 13 & $26 \%$ \\
\hline & Total & 50 & $100 \%$ \\
\hline
\end{tabular}

3.2. Pregnant women knowledge on Antenatal Care (ANC): Out of the 50 Participants, Majority 40(80\%) Had the right definition of Antenatal Care while a Lesser 4(8\%) Did Not

Table 2. Distribution of participant knowledge on ANC.

\begin{tabular}{lll}
\hline What is ANC & Frequency & Percentage \\
\hline $\begin{array}{l}\text { Care given to the pregnant woman during } \\
\text { breastfeeding }\end{array}$ & 4 & $8 \%$ \\
$\begin{array}{l}\text { Care given to the pregnant woman and her } \\
\text { unborn baby before the onset of labour }\end{array}$ & 40 & $80 \%$ \\
$\begin{array}{l}\text { Care given to the fetus } \\
\text { Total }\end{array}$ & 6 & $12 \%$ \\
\hline
\end{tabular}

\subsection{Pregnant Women Knowledge on the Component of ANC Services}

From the results, majority $30(60 \%)$ indicated Nutrition, environmental hygiene, breastfeeding, exercise, signs and symptoms of labour as topics taught during ANC while a lesser proportion 5(10\%) Personal and environmental hygiene as seen in the table below

Table 3. Distribution of knowledge of participant on topic taught during
$A N C$.

\begin{tabular}{lll}
\hline Knowledge on the topics taught during ANC & Frequency & Percentage \\
\hline $\begin{array}{l}\text { Nutrition, environmental hygiene, } \\
\text { breastfeeding, exercise, signs and symptoms of }\end{array}$ & 30 & $60 \%$ \\
$\begin{array}{l}\text { labor } \\
\text { Emergency items }\end{array}$ & 5 & $10 \%$ \\
$\begin{array}{l}\text { Personal and environmental hygiene } \\
\text { Adequate nutrition }\end{array}$ & 5 & $10 \%$ \\
Total & 10 & $20 \%$ \\
\hline
\end{tabular}

\subsection{Pregnant Knowledge on the Importance of $A N C$ Service}

Out of the 50 participants, majority $30(60 \%)$ of pregnant women said ANC is importance because it prevents maternal and child mortality while a lesser proportion $3(6 \%)$ to maintain a stable family relationship. Table 4

Table 4. Distribution on pregnant women knowledge on ANC importance.

\begin{tabular}{lll}
\hline Importance of ANC & Frequency & Percentage \\
\hline $\begin{array}{l}\text { To prevent maternal and child mortality } \\
\text { To prevent unwanted complications during } \\
\text { pregnancies e.g eclampsia }\end{array}$ & 30 & $60 \%$ \\
$\begin{array}{l}\text { To maintain a stable family relationship } \\
\text { To monitor health of mother and baby }\end{array}$ & 3 & $16 \%$ \\
Total & 9 & $6 \%$ \\
\hline
\end{tabular}

\subsection{Importance to Begin Antenatal Early}

From the result, majority $25(50 \%)$ of the participants say it is very importance to start ANC early, to check their health and that of the child while a lesser proportion $15(30 \%)$ say in importance because it prevent pregnancy complications. Table 5

Table 5. Distribution on the advantages of starting ANC early.

\begin{tabular}{lll}
\hline Importance of early ANC & Frequency & Percentage \\
\hline To check their health and that of their & 25 & $50 \%$ \\
To prevent pregnancy complications & 15 & $30 \%$ \\
To prevents maternal and child dead & 8 & $16 \%$ \\
To discuss some marital issues & 2 & $4 \%$ \\
Total & 50 & $100 \%$ \\
\hline
\end{tabular}

\subsection{Rating the Importance of Antenatal Care Services}

On a scale of 5 , giving that 5 (very important) and 1(less important), the results showed that majority 30(60\%) say ANC is important while a lesser proportion said they don't care much. Table 6

Table 6. Distribution on scale from 1-5 on the importance of ANC.

\begin{tabular}{ll|l}
\hline Scale from 1-5 & Frequency & Percentages (\%) \\
\hline Very importance & 12 & $24 \%$ \\
Importance & 30 & $60 \%$ \\
Neutral & 4 & $8 \%$ \\
$\begin{array}{l}\text { I do care but don't have } \\
\text { time }\end{array}$ & 3 & $6 \%$ \\
I don't care much & 1 & $2 \%$ \\
Total & 50 & $100 \%$ \\
\hline
\end{tabular}

3.7. Factor that Hinder Pregnant Women from Attending 


\section{ANC}

Out of the 50 participants, majority $19(38 \%)$ said it could be due to poverty, while a lesser proportion $3(6 \%)$ said it due to distance as shown below.

Table 7. Factors that hinder pregnant women from attending ANC.

\begin{tabular}{lll}
\hline Hinder to ANC & Frequency & Percentages (\%) \\
\hline Poverty & 19 & $38 \%$ \\
Culture/ religion & 12 & $24 \%$ \\
Lack of health facilities in some & 11 & $22 \%$ \\
remote areas & 3 & $6 \%$ \\
Distance & 5 & $10 \%$ \\
Illiteracy & 50 & $100 \%$ \\
Total & & \\
\hline
\end{tabular}

\section{Discussion}

This study aimed at identifying the knowledge of pregnant women on antenatal care and the factors that hinder the attendance.

Looking at the pregnant women knowledge on the component of ANC reveal that $72 \%$ are aware and had knowledge on ANC as they defined it as a pregnancy related services provided to pregnant women by health professional, aimed at preventing neonatal deaths and maintaining the health of women during pregnancy. This is in line with Darmstadt et al. [2] who concluded that ANC is a practice which is aimed at promoting the health of the mother and the neonate.

Based on the knowledge about ANC, majority (96\%) of the respondents know the components of ANC which are consultation and family planning. This is in line with WHO, 2005 report which stated that the components of ANC are consultation, family planning, Laboratory investigation, health education. [9]

However, a lesser proportion of respondents $4(8 \%)$ did not know the components of ANC because of ignorance which is confirm by WHO, 2011 which state ANC challenges are influence by ignorance, culture, tradition and religious practices, lack of women's autonomous decision making, poverty and more over illiteracy. [3, 5]

As reflected, all the women had knowledge on topics taught during $\mathrm{ANC}$, as they listed adequate nutrition, environmental hygiene, breast feeding, exercise, signs and symptoms of labour, medications and emergency item, which correspond with WHO, 2014 ideas which state that topics on adequate nutrition, medication, lifestyle, exercise, personal and environmental hygiene, breast feeding, signs and symptoms of labour are topics of ANC. [6]

With regard to pregnant women knowledge on the importance of ANC services, 94\% said ANC is importance on their health and that of their neonate which was concluded by WHO, 2006 which stated that ANC foster a rapport between the mother and the father and the health care provider, provide preventive care and health education, identify and treat illness, encourage skilled attendance at birth and prepare the mother and other family members and birth attendants for possible emergency.

Also, 74\% of these pregnant women know the importance of starting ANC early which is confirm by WHO, 2013 which stated the time for the various visits i.e. first visit from 12 weeks, second visit from $20-28$ weeks, third visit from $28-36$ weeks and fourth visit from 36 weeks.

It can be seen from the results that majority $(38 \%)$ of the respondents said that poverty is one of the factors that hinders ANC, while a lesser proportion said it is due to lack of health facilities, and distance. This is in line with WHO (2013) which stated that factors that hinder ANC are poverty, lack of health centers, distance. [5]

With regard to pregnant women knowledge on the respect of ANC visits, $84 \%$ of these women said they keep to their next visit this is in line with. $[8,10]$ Which stated that all pregnant women should keep to their next visit.

Notwithstanding a lesser proportion (6\%) said they do not respect their ANC visit due to economic barrier. This is not in line with WHO (2013) which started that pregnant women should go for regular ANC so as to prevent pregnancy complications. [5]

\section{Conclusion}

From the above results, it can be concluded that adequate knowledge reduces maternal and infant mortality it was observed that pregnant women have knowledge on ANC as they were able to identify the key components of ANC.

Also, ANC is important especially when started early, because there are some advantages which involves early morbidity of the neonate and the mother so that appropriate medication will be giving.

And finally, women identified some hindrances for not going for ANC and most of them complained of poverty as the key hindrance.

\section{Recommendation}

We can therefore recommend that, The ministry of public health should organize ANC campaigns for all pregnant woman to attend for free so as to increase their knowledge in relation to their pregnancy.

Health Practitioners should encourage women to attend ANC and to start it early to easily detect any complication with the neonate or mother.

The hospital's administration should reduce the fees of pregnant women attending ANC so as to encourage the women to attend.

\section{Acknowledgement}

My profound gratitude goes to: The staffs and patients of the Buea Regional Hospital, for allowing us to carry out this study, and for their participation and support; Thanks goes to UPCAWA SWEDEN for putting together the research team and their support. 


\section{Appendix 1}

Questionnaire

Section A; Demography Data

1) Age range[a]16-19,[b]20-25,[c]26-30,[d]30-35,[35 and above]

2) Religion [a] Christain, [b] Muslim [c] others

3) Marital Status [a] Married [b] Single [c] widows [d] Divoce

4) Profession [a] FSLC [B] Odinary level [c] Advance level [d] Others

Section $B$

Answered yes or no

Pregnant women knowledge on the component of ANC

1) What is ANC

\begin{tabular}{|c|c|c|}
\hline Meaning of ANC & Agreed & Disagreed \\
\hline $\begin{array}{l}\text { It is a clinical assessment of mother during } \\
\text { pregnancy }\end{array}$ & & \\
\hline $\begin{array}{l}\text { It is a care given to the pregnant woman during } \\
\text { breastfeeding }\end{array}$ & & \\
\hline It is care given to the fetus & & \\
\hline $\begin{array}{l}\text { It is care given to the pregnant woman and her } \\
\text { unborn child before the onset of labour }\end{array}$ & & \\
\hline
\end{tabular}

2) What are the component of ANC

\begin{tabular}{ll}
\hline Components of ANC & Agreed \\
\hline Disagreed \\
Fansultation and health education & \\
Laboratory investigations & \\
Nutrition & \\
Basic and comprehensive emergency obstetric care & \\
\hline
\end{tabular}

3) Topics taught during ANC

\begin{tabular}{ll|l}
\hline Topics taught during ANC & Agreed & Disagreed \\
\hline Adequate nutrition & & \\
Breastfeeding & & \\
Abortion & & \\
Emergency items & & \\
Personal and environmental hygiene & \\
\hline
\end{tabular}

Section $C$

4) Pregnant woman knowledge on the important of ANC

\begin{tabular}{lll}
\hline Importance of ANC & Agreed & Disagreed \\
\hline To prevent unwanted complications during & \\
pregnancy & \\
To prevent maternal and child mortality & \\
To foster good husband and wife,mother and & \\
child, father and child relationship & \\
To encourage unwanted pregnancy & \\
To check the health of their baby & \\
\hline
\end{tabular}

5) Is there any advantage of starting early ANC

\begin{tabular}{|c|c|c|}
\hline $\begin{array}{l}\text { advantage of early anc } \\
\text { yes } \\
\text { no }\end{array}$ & Agreed & Disagreed \\
\hline
\end{tabular}

6) On a scale of 1-5, how important is ANC service to pregnant women

\begin{tabular}{lll}
\hline Scale of 1-5 & Agreed & Disagreed \\
\hline Very important & \\
Important & \\
Neutral & \\
I do care but don't have time & \\
I don't care much & \\
Total & \\
\hline
\end{tabular}

7) Pregnant women knowledge on respect to ANC

\begin{tabular}{lll}
\hline Respect to ANC & Agreed & Disagreed \\
\hline Yes & & \\
No & & \\
\hline \multicolumn{2}{l}{ Section $D$} \\
8) Factors that hinders pregnant women from using ANC \\
services & & \\
\hline Hindrance to ANC & Agreed & Disagreed \\
\hline Lack of adequate knowledge & & \\
Religion and cultural barrier & & \\
Lack of health facilities in some health areas & & \\
Lack of money & & \\
Distance and waste of time & \\
\hline
\end{tabular}

9) Other factors that hinders pregnant women from using ANC services

\begin{tabular}{lll}
\hline Other factors that hinders ANC & Agreed & Disagreed \\
\hline Economic barrier & & \\
Cultural belief & & \\
Household responsibilities & \\
Social barrier & \\
Ignorance & \\
Shortage of supplies & \\
Lack of communication & \\
\hline
\end{tabular}

\section{Appendix 2}

Operational Defination of Terms

Antenatal care: is one of the evidence based interventions to decrease the probability of bad health outcomes for mothers and their newborns.

Pregnancy: is a period of conception to birth.

Health: it is a state of physical, mental, social wellbeing and not merely the absence of a disease.

Amenorrhea: is a profuse bleeding from rupture blood vessels.

Eclampsia: is a life threatening complication of pregnancy, it is a condition that causes a pregnant women previously diagnosed with pre-eclampsia (high blood pressure, protein in urine) to develop seizure or coma.

Morbidity: a disease state or symptom or incidence of disease.

Mortality: a condition of being mortal or death.

Maternal mortality: according to WHO, is the death of a woman while pregnant or within 42 hours of termination of pregnancy, irrespective of the duration and site of pregnant, from any cause related to or aggravated by the pregnancy or its management but not from accident or incidental causes (WHO, 2014).

Immunization: is a process of an artificial introduction of immunity in an effort to protect against infectious diseases of 
an individual defensive system.

Disease: is a definite pathological process of having a characteristic set of signs and symptoms.

Infection: is the invasion of the body by organism causing disease.

Insecticide: is a chemical used specifically to kill or control the growth of insects

\section{References}

[1] Rooney CIF. Antenatal Care and Maternal Health: How Effective Is It? Geneva, Switzerland: Documment WHO/MSM/92A, World Health Organisation; 1992.

[2] Darmstadt GL, Bhuttta ZA, Cousens S, Adam T, Walker N, de Bernis L. Lancet Neonatal Survival Steering Team EvidenceBased, cost-effective interventions: how many newborn babies can we save? Lancet.2005; 365(9463): 977-988.

[3] WHO: Statement on antenatal Care January 2011, WHO/RHR/11012mja VOL 17618 March 2002 pp153/4, Guiding antenatal care $\mathrm{ABC}$ of Antenatal care, fourth edition, GEOFFERY CHAMBELIN.
[4] Minsante' (2011). Campagne pour L'Acce'leration de la Re'duction de la Mortalite' Maternelle et Infantile (CARMMA) au Cameroun (2011-2013). Yaounde': Ministere de la Sante' publique.

[5] WHO, UNICEF, UNFPA, and the World Bank, Trends in maternal Mortality: 1990 to 2013, WHO, Geneva, 2014.

[6] WHO: Trends in maternal mortality: 1990-2008: Estimates Developed by WHO, UNICEF, UNFPA, and the World Bank. Geneva, Switzerland: World Health Org; 2010.

[7] Prual A, Toure A, Huguet D, Laurent Y; The quality of risk factor screening during antenatal consultation in Niger. Health policy plan 2000, 15(1) 11-16.

[8] Africa Progress Panel. (2010). Maternal Health: Investing in lifeline of health societies and economies. Africa Progress Panel.

[9] World Health Organisation. The World Health Report: 2005: Make Every Mother and Child count. Geneva: World Health Org. 2005.

[10] World Bank (2008). Project Appraisal Document for a Health Sector Support Investment Cameroon. Washington, DC: World Bank HHP. 